\title{
Correspondence
}

\section{Hazards of analgesia for newborn infants}

Sir,

Over recent months there have been many communications exhorting paediatricians and anaesthetists to prescribe analgesics for newborn infants. ${ }^{12}$ Such prescriptions are not without risk with problems mainly manifesting as respiratory or cardiovascular depression. Indeed opiates are frequently used to stop an infant struggling against the ventilator. Little is known, however, about how preterm infants handle opiate analgesics. We therefore undertook a study of alfentanil pharmacokinetics in preterm infants undergoing paralysis and mechanical ventilation for respiratory distress syndrome. Alfentanil was chosen because of its rapid distribution and short half life in adults and older children. We were concerned that other drugs may have such prolonged excretion rates that accumulation might occur with repeated doses. For example, among preterm infants undergoing surgery for patent ductus arteriosus the half life of fentanyl may be prolonged to over 17 hours compared with two hours in adults. ${ }^{3}$ There are no comparable data for other opiates. Our aim was to establish a regime for continuous infusion or safe regular bolus dosage.

This study was approved by the local ethical committee. The pharmacological data will be reported separately. Recordings were made for 20 children, median gestation 30 weeks (range 25-36), median birth weight $1348 \mathrm{~g}$ (range $690-4084)$ at $<24$ hours age $(n=10), 25-48$ hours $(n=5)$, and 49-84 hours $(n=5)$. All children had indwelling arterial catheters and continuous direct blood pressure monitoring.

The intravenous administration over two minutes of $20 \mu \mathrm{g} / \mathrm{kg}$ alfentanil produced a rapid and significant fall in both heart rate and blood pressure (table). Arterial oxygenation worsened but there was no change in $\mathrm{PaCO}_{2}$ or $\mathrm{pH}$. This occurred despite a smaller loading dose than the recommended $30-50 \mu \mathrm{g}$ and slow intravenous injection.

In the preterm infant fluctuations in blood pressure and specifically hypotension have been associated with periventricular haemorrhage and periventricular leucomalacia. Although the sedative effect of opiates may reduce variability of blood pressure ${ }^{4}$ any hypotensive effect remains of great concern. Thus despite calls for the administration of opiates to ventilated preterm infants, we urge proper evaluation of their pharmacological and clinical effects before their use becomes widespread.

\footnotetext{
References

1 Fletcher AB. Pain in the neonate. $N$ Engl J Med 1987;317: 1347-8.

2 Anand KJS, Sippel WG, Aynsley-Green A. Randomised trial of fentanyl anaesthesia in preterm babies undergoing surgery. Lancet 1987;i:243-8.

3 Collins C, Koren G, Crean P, Klein J, Roy WL, Macleod SM. The correlation between fentanyl pharmacokinetics and pharmacodynamics in preterm infants during patent ductus arteriosus ligation. Anesthesiology 1984;61:A442.

${ }^{4}$ Miall-Allen VM, Whitelaw AGL. Effect of pancuronium and pethidine on heart rate and blood pressure in ventilated infants. Arch Dis Child 1987;62:1179-80.
}
N Marlow, A M Weindling, and R W I COOKE Department of Child Health, Liverpool Maternity Hospital, Oxford Street, Liverpool L7 7BN

Table Physiological responses to $20 \mu \mathrm{g} / \mathrm{kg}$ alfentanil $(n=20)$. Results expressed as median (range)

\begin{tabular}{|c|c|c|c|c|c|}
\hline Time & $\begin{array}{l}\text { Heart rate } \\
\text { (bpm) }\end{array}$ & $\begin{array}{l}\text { Mean blood } \\
\text { pressure } \\
(\mathrm{mm} \mathrm{Hg})\end{array}$ & $\begin{array}{l}\mathrm{PaO}_{2} \\
(\mathrm{kPa})\end{array}$ & $\begin{array}{l}\mathrm{PaCO}{ }_{2} \\
(k P a)\end{array}$ & $p H$ \\
\hline $\begin{array}{l}\text { Baseline } \\
\text { Baseline plus: }\end{array}$ & $153(127-193)$ & $44 \cdot 5(25-55)$ & $8 \cdot 0(4 \cdot 7-12 \cdot 9)$ & $5.4(2 \cdot 8-9.9)$ & $7.33(7.03-7.39)$ \\
\hline 2 minutes & $153(129-194)$ & $40 \cdot 5(30-54)$ & & & \\
\hline 3 minutes & $151(134-194)$ & $37.0(29-51)$ & & & \\
\hline 4 minutes & $150(131-193)$ & $35 \cdot 5(29-49)$ & & & \\
\hline 5 minutes & 149 (131-193) & $35.0(29-48)$ & & & \\
\hline 6 minutes & $150(130-193)$ & $36 \cdot 0(28-47)$ & $7 \cdot 5(4 \cdot 4-13 \cdot 3)$ & $5 \cdot 6(4 \cdot 5-9 \cdot 2)$ & $7 \cdot 33(7 \cdot 21-7 \cdot 38)$ \\
\hline p Value & 0.014 & $<0.0001$ & 0.005 & NS & NS \\
\hline
\end{tabular}

Significances of differences between baseline and 6 minute values tested with paired $t$ test. 